\title{
Pseudomonas exotoxin-Anti-TAC \\ Cell-specific Immunotoxin Active against Cells Expressing the Human T Cell Growth Factor Receptor
}

David J. P. FitzGerald, Thomas A. Waldmann, Mark C. Willingham, and Ira Pastan

Laboratory of Molecular Biology and Metabolism Branch, Division of Cancer Biology and Diagnosis, National Cancer Institute, National Institutes of Health, Bethesda, Maryland 20205

bstract. An immunotoxin was constructed with an activity that discriminated between two $T$ cell lines based on the expression of the $\mathrm{T}$ cell growth factor (TCGF) receptor on their cell surface. A toxic protein conjugate, designated PE-anti-TAC, was made by chemically coupling pseudomonas exotoxin (PE) to a monoclonal antibody (anti-TAC) that recognizes the human TCGF receptor. This conjugate was toxic to HUT-102 cells, a cell line that expresses the TCGF receptor, but was nontoxic for MOLT-4 cells, a receptor-negative line. The toxicity of PE-anti-TAC was enhanced 50-fold in the presence of human adenovirus type II and was reduced to control levels by adding excess anti-TAC antibody. The toxicity of PE-anti-TAC for HUT-102 cells was compared with $\mathrm{PE}$-anti-transferrin receptor. To compare the route of entry for both anti-TAC and anti-TFR using electron microscopy, protein conjugates were made by coupling horseradish peroxidase (HRP) to each antibody. Anti-TFR-HRP entered HUT-102 cells by concentrative adsorptive endocytosis via coated pits, and the majority of the antibodies bound to the cell surface at $4^{\circ} \mathrm{C}$ were seen in receptosomes by 10 min after warming to $37^{\circ} \mathrm{C}$. Anti-TAC-HRP was also found to enter HUT-102 cells via coated pits and receptosomes; but, in contrast to anti-TFR, anti-TAC did not selectively concentrate in coated pits, and therefore the majority of this surface-bound antibody were not internalized in HUT-102 cells by $10 \mathrm{~min}$ at $37^{\circ} \mathrm{C}$.

Received for publication 17 January 1984 and in revised form 23 April 1984.

The Journal of Clinical Investigation

Volume 74, September 1984, 966-971

\section{Introduction}

Currently, there is great interest in using cell-specific antibodies to construct immunotoxins for use in cancer chemotherapy and other therapies where it is desirable to kill specific populations of cells (see references 1-3 for reviews). Ideally, immunotoxins should discriminate to a high degree between target and nontarget tissue. Such is not possible, for instance, with immunotoxins that are directed against the transferrin receptor, where many cell types are likely to be susceptible even if the receptor is enriched on target cells (4). Thus it is important to develop immunotoxins that are highly toxic for specific populations of cells.

Anti-TAC, a monoclonal antibody that was first described by Uchiyama et al. $(5,6)$, recognizes the human $T$ cell growth factor (TCGF)' receptor on several TAC-antigen-positive cell types (7). Anti-TAC reacts with the TCGF receptor on both antigen (or mitogen) activated $\mathrm{T}$ cells and on all $\mathrm{T}$ cell lines that are infected with human $\mathrm{T}$ cell leukemia virus (HTLV) $(7,8)$. HTLV is a C type retrovirus that is associated with a cutaneous $\mathrm{T}$ cell lymphoma/leukemia known as adult $\mathrm{T}$ cell leukemia $(9,10)$. The HUT-102 cell line, which was derived from an adult $\mathrm{T}$ cell leukemia patient, grows well in tissue culture, expresses the TCGF receptor, and is reactive with anti-TAC (7). MOLT-4 is a long-term T cell line that does not bind TCGF (interleukin 2) and is nonreactive for anti-TAC (5). Neither cell line requires exogenous TCGF for growth. Both cell lines are reactive, as are virtually all cell lines of human origin, with antibodies that recognize the human transferrin receptor (TFR) (4).

To construct a "successful" immunotoxin, using a cellbinding antibody and a protein toxin, one must select an antibody that is capable of efficient internalization and delivery of the toxin to its intracellular target. Previous studies have

1. Abbreviations used in this paper: anti-TAC, antibody that recognizes the human TCGF receptor; HRP, horseradish peroxidase; HTLV, human T cell leukemia; PHA, phytohemagglutinin; PE, pseudomonas exotoxin; PE-Ab, PE antibody; TFR, transferrin receptor. 
demonstrated that at least two monoclonal antibodies (B3/25, HB21) that recognize the human TFR are internalized efficiently into cultured human cell lines via coated pits and receptosomes (11). These antibodies were used to construct cytotoxic molecules by chemically coupling them to either pseudomonas exotoxin (PE) or to the A-chain of ricin $(4,11)$. In this study, anti-TAC was used to construct a cell-specific immunotoxin with HUT-102 cells as the target cells. To do this, anti-TAC was coupled to PE and assayed to TCGF receptor positive and negative cell lines. Further, adenovirus, which was shown previously to enhance the toxicity of various toxin conjugates (12), was assayed for its ability to potentiate PE-anti-TAC activity. Using electron microscopy, a morphologic investigation was carried out of the site of initial interaction of anti-TAC with HUT-102 cells. The activity of the anti-TAC conjugate and the cellular location of the antibody were compared with those of an antibody to the transferrin receptor.

\section{Methods}

Cells. HUT-102 and MOLT-4 cells were grown in suspension in RPMI $1640,10 \%$ fetal bovine serum (Gibco Laboratories, Grand Island, NY), and pencillin-streptomycin.

Pseudomonas exotoxin. PE was the generous gift of S. A. Leppla, Fort Detrick, Federick, MD.

Antibodies. Anti-TAC and anti-TFR (HB21-ATCC) were purified from ascites fluid according to methods previously described (13). Anti-TAC is an IgG2a antibody (5) and $\mathrm{HB}_{21}$ an $\mathrm{IgG}_{1}(14)$. The HB21 antibody is designated anti-TFR throughout this report. RPC 5, an irrelevant IgG2a antibody, was purchased from Litton Bionetics, Kensington, MD.

Virus. Human adenovirus type II was propagated in KB cells that were grown in suspension culture and purified as described $(12,15)$.

Antibody conjugates with $P E$. Conjugates were constructed by disulfide exchange as described previously (11). PE-antibody (PE-Ab) molecules were purified by a two-step procedure. Typically, $1 \mathrm{ml}$ of conjugate at 3-5 mg/ml was passed over a Sepharose 6-B column. Large aggregates in the void volume were of low activity and were discarded. The included protein was further purified and separated from unreacted, derivatized PE on a G-200 column. Tracer amounts of ${ }^{125} \mathrm{I}-\mathrm{PE}$ were used to follow the separation. As has been noted before, the coupling of PE to antibody molecules did not diminish the enzyme activity of this toxin $(11,12)$. Routinely, the antibody and PE toxin were coupled in the ratio of one toxin to two antibody molecules (Ab-PE-Ab).

Antibody conjugates with horseradish peroxidase (HRP). Antibody conjugates with HRP were made in a similar fashion to the toxin conjugates. HRP and each antibody were initially reacted with methyl 4-mercaptobutyrimidate to introduce an average of one new sulfydryl group per protein molecule. The disulfide linkage was completed after the addition of dithionitrobenzoate to the methyl 4-mercaptobutyrimidate-treated HRP.

Toxicity studies of PE-conjugates on HUT-102 and MOLT-4 cells. Cells were diluted in RPMI 1640, 10\% fetal bovine serum, and penicillin-streptomycin, and aliquoted to give $\sim 4 \times 10^{5}$ cells $/ 35-\mathrm{mm}$ dish. PE-Ab additions were made from concentrated stock solutions directly into the cell cultures. Human adenovirus type II (ultraviolet inactivated to $10^{-8}$ of original infectivity) was added where indicated from a stock vial that contained $2 \mathrm{mg} / \mathrm{ml}$ (protein) of virus. The final concentration of virus for cell cultures was $2 \mu \mathrm{g} / \mathrm{ml}$. After the appropriate incubation periods, $\left[{ }^{3} \mathrm{H}\right]$ leucine was added to the dishes for $1 \mathrm{~h}$ at a concentration of $\sim 4 \mu \mathrm{Ci} / \mathrm{ml}$. For determination of protein synthesis levels, cells were washed in phosphate-buffered saline (PBS), the cell pellet solubilized with $0.1 \mathrm{M} \mathrm{NaOH}$, and the number of counts in TCA precipitable material was determined. For both the HUT-102 and MOLT-4 lines, $7.5-10 \times 10^{4} \mathrm{cpm} /$ dish was typical for control cells.

Electron microscopic localization of anti-TAC-HRP and HB21HRP on HUT-102 cells. HUT-102 cells were washed by centrifugation and resuspended in cold $\left(4^{\circ} \mathrm{C}\right)$ PBS-bovine serum albumin (BSA). Anti-TAC-HRP or HB21-HRP was added at a concentration of 100 $\mu \mathrm{g} / \mathrm{ml}$ in PBS-BSA for $1 \mathrm{~h}$. After this binding step, the cells were washed three times by centrifugation at $10,000 \mathrm{~g}$ for $30 \mathrm{~s}$, resuspended in PBS-BSA, and added to poly-L-lysine-treated 35-mm dishes $\left(4^{\circ} \mathrm{C}\right)$ for $1 \mathrm{~h}$. This allowed the cells to attach to the plastic. After equilibrating for $1 \mathrm{~h}$, the dishes were washed to remove loosely attached cells, then either fixed immediately or warmed to $37^{\circ} \mathrm{C}$ for 1 or $10 \mathrm{~min}$. Cells were fixed in $2 \%$ glutaraldehyde and processed for electron microscopy, as described previously (11). Thin sections were prepared with a Sorvall MT-5000 ultramicrotome and a diamond knife and, after lead citrate counterstaining, were viewed with a Hitachi HU-12A electron microscope that was operated at $50 \mathrm{kV}$.

Antibody binding to HUT-102 cells and phytohemagglutinin (PHA)treated peripheral blood lymphocytes. Anti-TAC was labeled with tritium by reductive methylation to a high specific activity $(7.3 \mu \mathrm{Ci} /$ $\mu \mathrm{g})$ (16). Anti-TFR was radioiodinated by a modified iodo-gen procedure (17) to a specific activity of $9 \mu \mathrm{Ci} / \mu \mathrm{g}$. Peripheral blood mononuclear cells or T cells were cultured with PHA and anti-TAC binding was assayed after 3-4 d. HUT-102 cells, taken directly from tissue culture, were used to assess anti-TFR binding. Both cell types were washed twice in binding medium (RPMI 1640,1\% BSA, $1 \mathrm{mg} / \mathrm{ml}$ human IgG, $0.1 \%$ azide) before antibody additions. The presence of azide allowed binding assessments to be made at $23^{\circ} \mathrm{C}$ rather than in the cold. Binding experiments were performed in $1.5-\mathrm{ml}$ centrifuge tubes on a rocking platform. From preliminary experiments, equilibrium binding was achieved for both antibodies at $\sim 45 \mathrm{~min}$. The results presented represent the average of triplicate samples with a binding time of 60 min. Standard derivations for each point were $<10 \%$ of the mean. From a starting cell concentration of $2 \times 10^{7} / \mathrm{ml}, 50 \mu \mathrm{l}$ was added to the reaction tube, then $20-30 \mu l$ of unlabeled antibody (or immunotoxin), and finally $20 \mu \mathrm{l}$ of radiolabeled antibody. The radiolabeled antibody was kept at a constant concentration (well below half saturation) while the unlabeled antibody was varied over a wide range to determine the concentration of each antibody species that displaced half the labeled antibody. At the end of $60 \mathrm{~min}$ the cells were transferred to a second tube, which contained PBS, to which sucrose was added to a 1-M concentration. After the appropriate washings, the cell pellet was collected and counted in the appropriate beta or gamma counter.

\section{Results}

Toxicity of PE-anti-TAC for HUT-102 and MOLT-4 cells. PE-anti-TAC was added to cells at $37^{\circ} \mathrm{C}$ and the ability of this conjugate to inhibit protein synthesis was determined after a 20-h incubation (Fig. 1). The activity of PE-anti-TAC was 


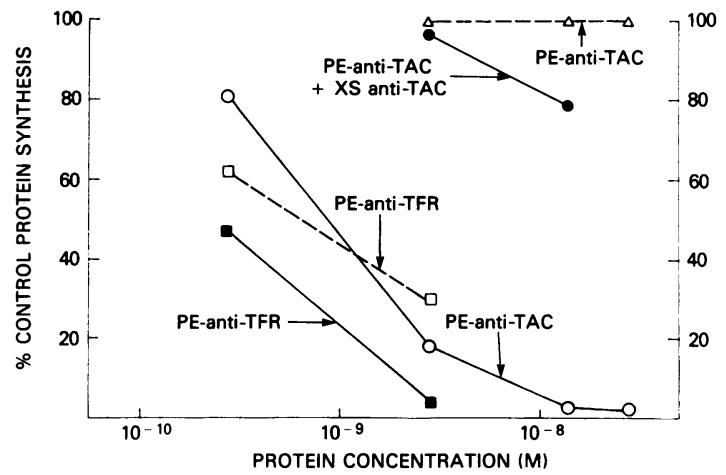

Figure 1. Inhibition of protein synthesis by PE immunotoxin when added to HUT-102 (solid lines) or MOLT-4 (broken lines). Immunotoxins were added to cells in small volumes from stock solutions to give the final concentrations indicated above. Cells were incubated at $37^{\circ} \mathrm{C}$ for $20 \mathrm{~h}$ and $\left[{ }^{3} \mathrm{H}\right]$ leucine $(3-4 \mu \mathrm{Ci} / \mathrm{ml}$, final concentration) was added for a further $1 \mathrm{~h}$. Control dishes incorporated $\approx 70,000 \mathrm{cpm}$ into TCA insoluble material. XS, excess.

compared with a conjugate of PE coupled to an antibody against the transferrin receptor (PE-anti-TFR) by assaying each conjugate on HUT-102 and MOLT-4 cells. Both these cell types contain TFRs, but only HUT-102 cells contain TCGF receptors $(5,18)$. Both cell types responded to the PEanti-TFR conjugate, with the MOLT-4 cell line being two- to threefold less sensitive (Fig. 1). 50\% inhibition of protein synthesis occurred at $2.5 \times 10^{-10} \mathrm{M}$ for HUT-102 and 6.5 $\times 10^{-10} \mathrm{M}$ for MOLT -4 . In contrast, there was at least a 100 fold difference in the response of HUT-102 and MOLT-4 cells to PE-anti-TAC. PE-anti-TAC caused a $50 \%$ reduction in protein synthesis at $9 \times 10^{-10} \mathrm{M}$ with HUT-102 cells (an additional purification step, using a TSK-250 HPLC column, produces PE-anti-TAC that inhibits $(50 \%)$ protein synthesis of HUT-102 cells at $5 \times 10^{-11} \mathrm{M}$ ). There was no detectable reduction of protein synthesis when PE-anti-TAC was added to MOLT-4 cells at concentrations as high as $3 \times 10^{-8} \mathrm{M}$. Thus, PE-anti-TAC was cytotoxic for cells expressing the TCGF receptor but inactive against receptor negative cells.

The specificity of PE-anti-TAC toxicity was determined by adding PE-anti-TAC in the presence of excess unconjugated anti-TAC antibody. PE-anti-TAC toxicity was reduced by $\sim 50$-fold in the presence of $1.8 \times 10^{-7} \mathrm{M}$ anti-TAC antibody. No reduction of toxicity was seen when PE-anti-TAC was added to cells in the presence of the same concentration of an irrelevant IgG2a (RPC 5) antibody. Reduction of toxicity by excess anti-TAC is discussed below.

Adenovirus-mediated enhancement of PE-anti-TAC toxicity. Human adenovirus type II enters cells by receptor-mediated endocytosis $(12,19)$ and begins to escape into the cell cytosol 2-5 min after it is delivered from coated pits into receptosomes. In human fibroblasts and human KB cells, it was found that the virus allowed ligands cointernalized with the virus to be released into the cytosol $(11,12)$. When the ligand was a toxin or a toxin conjugate, there was an enhancement of toxicity compared with the addition of toxin alone. To determine if the phenomenon occurred in lymphoid cells, adenovirus (2 $\mu \mathrm{g} / \mathrm{ml}$ ) and PE-anti-TAC were incubated with HUT-102 cells (Fig. 2). As observed with the other human cell types, adenovirus enhanced toxicity. Toxocity of PE-anti-TAC was enhanced $\sim 50$-fold in the presence of adenovirus $(2 \mu \mathrm{g} / \mathrm{ml})$ when compared with the addition of PE-anti-TAC alone.

Morphological characterization of the initial uptake of antiTAC-HRP and anti-TFR-HRP by HUT-102 cells. HRP was conjugated to either anti-TAC or anti-TFR to form conjugates suitable for cytochemistry with electron microscopy. HUT102 cells were incubated with anti-TAC-HRP or anti-TFRHRP for $1 \mathrm{~h}$ at $4^{\circ} \mathrm{C}$, washed and allowed to adhere to poly-Llysine coated dishes for a further $1 \mathrm{~h}$. Then the cells were warmed to $37^{\circ} \mathrm{C}$ for either 1 or $10 \mathrm{~min}$ and fixed. Immobilization of cells as a monolayer by poly-L-lysine was necessary to allow the substrate for HRP to gain access to the cells.

At $1 \mathrm{~min}$ after warming to $37^{\circ} \mathrm{C}$, the cells showed labeling diffusely over the cell surface for both conjugates; and there was also extensive clustering in clathrin-coated pits with antiTFR-HRP (Fig. $3 A$ ), which was not seen with anti-TACHRP (Fig. $3 C$ ). This indicated that the anti-TAC conjugate did not selectively concentrate in coated pits. At 10 min after warming, the surface was substantially cleared of anti-TFRHRP, but large amounts of anti-TAC-HRP remained diffusely distributed on the cell surface (Fig. $3, B$ and $D$ ). At this time, some coated pits still showed heavy labeling of anti-TFR, whereas the concentration of anti-TAC-HRP in coated pits remained the same as the surrounding plasma membrane. At $10 \mathrm{~min}$ after warming, both conjugates were also found in receptosomes. Anti-TFR-HRP was present at a very high

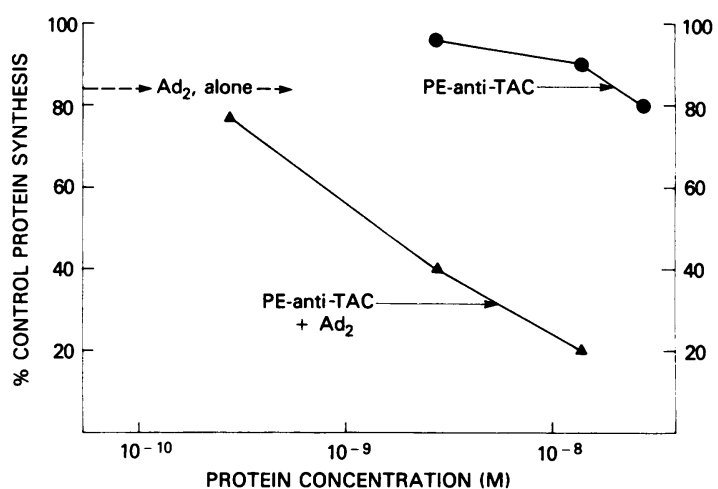

Figure 2. Enhancement of PE-anti-TAC toxicity by adenovirus. PEanti-TAC alone, adenovirus alone $(2 \mu \mathrm{g} / \mathrm{ml})$, or PE-anti-TAC plus adenovirus $(2 \mu \mathrm{g} / \mathrm{ml})$ were added to HUT- 102 cells for $4 \mathrm{~h}$ at $37^{\circ} \mathrm{C}$. At that time $\left[{ }^{3} \mathrm{H}\right]$ leucine was added to a final concentration of 3-4 $\mu \mathrm{Ci} / \mathrm{ml}$ for a further $1 \mathrm{~h}$. Protein synthesis inhibition was then determined by measuring the reduction in radioactivity incorporated into TCA insoluble material from treated cells vs. control cells that received no additions of toxins or virus. $\mathrm{Ad}_{2}$, adenovirus type II. 

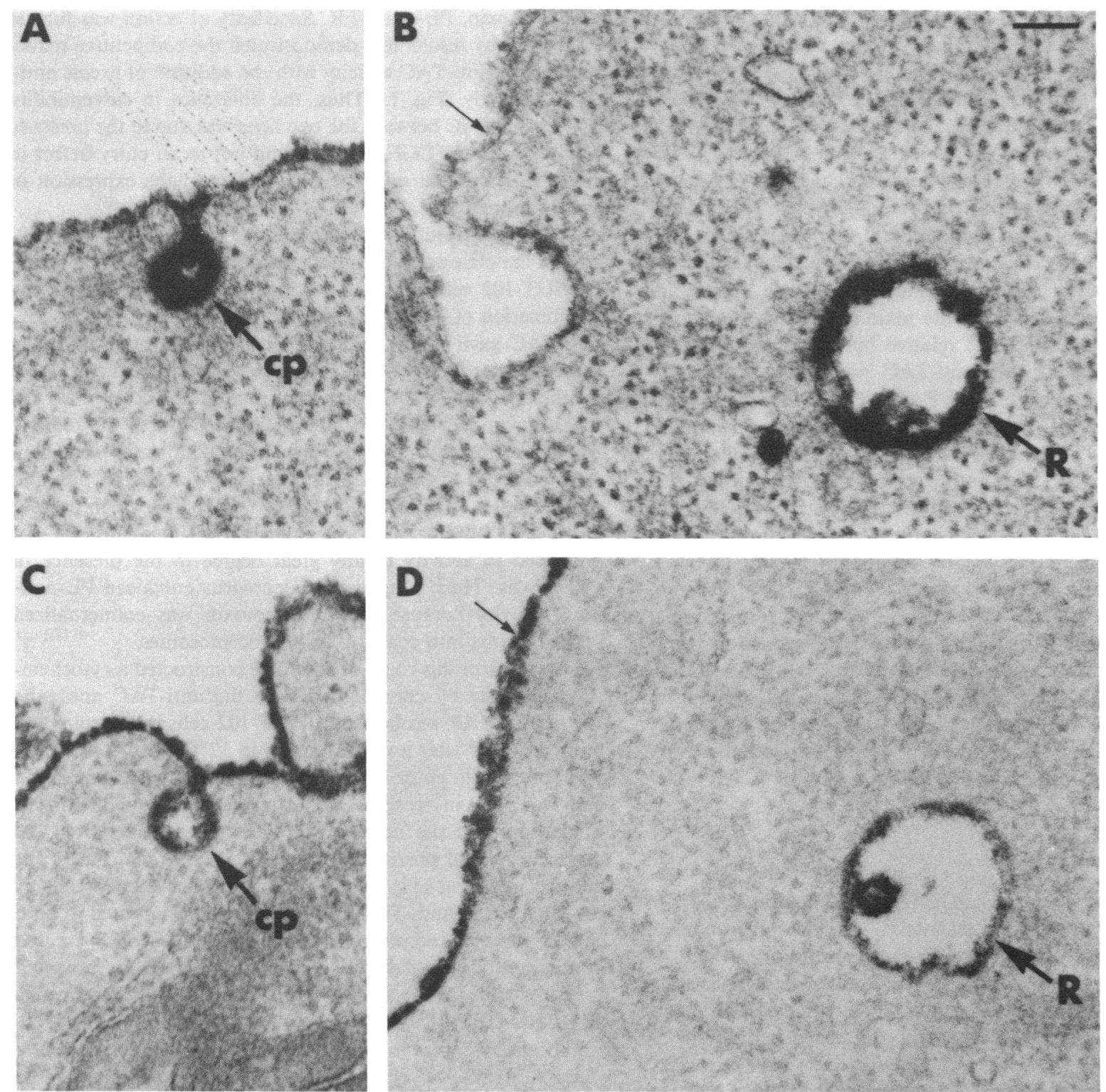

Figure 3. Morphologic appearance of anti-TAC-HRP and anti-TFRHRP after addition to HUT-102 cells. Anti-TFR-HRP, previously bound to cells at $4^{\circ} \mathrm{C}$, was warmed to $37^{\circ} \mathrm{C} 1 \mathrm{~min}(A)$ or $10 \mathrm{~min}(B)$. Likewise, $C$ and $D$ represent 1 and 10 min warm-up times for anti-

concentration which reflected the concentration seen in coated pits from which these receptosomes were derived. An example is shown in Fig. $3 B$. It is important to compare the large amount of anti-TFR-HRP present in receptosomes with the low levels of anti-TFR-HRP seen on the plasma membrane of the same cell (Fig. $3 \mathrm{~B}$ ). In contrast, the concentration of anti-TAC-HRP in receptosomes was lower and appeared to be the same or less than its concentration on the plasma
TAC-HRP. After fixation with glutaraldehyde, samples were treated with diaminobenzidine and hydrogen peroxide to localize the peroxidase activity of the antibody-HRP conjugate (bar equals $0.1 \mu \mathrm{m}$ ).

membrane of the same cell (Fig. $3 \mathrm{D}$ ). This result agrees with the lack of selective concentration of this ligand in coated pits (Fig. $3 C$ ). These differences in the concentration of antiTFR-HRP and anti-TAC-HRP were consistently seen in over 100 cell profiles that were examined with each of the two conjugates, and the examples shown here are typical. With anti-TAC-HRP, the label in a receptosome was never greater than on the plasma membrane of the same cell. With anti- 
TFR-HRP the label in receptosomes and coated pits was always more concentrated than on the rest of the plasma membrane. These studies indicate that both ligands enter cells by coated pits and receptosomes, and that anti-TFR-HRP is selectively concentrated in coated pits before entry, whereas anti-TAC-HRP is not.

Residual immunotoxin cell-binding activity. After the coupling of PE to either anti-TAC or anti-TFR, the residual cellbinding activity of each immunotoxin was determined. Only antibody binding was assessed, since we have shown that the chemical coupling of PE to epidermal growth factor and various antibodies destroyed the toxin's ability to bind to its own receptor $(11,12)$. The relative binding activity of PEanti-TAC compared with anti-TAC was assessed on PHAstimulated lymphocytes, and PE-anti-TFR with anti-TFR on HUT-102 cells. PE-anti-TAC was not assayed for binding activity of HUT-102 cells for technical reasons that were related to the very large number of anti-TAC binding sites (22). ${ }^{3} \mathrm{H}$-anti-TAC $\left(3.5 \times 10^{-10} \mathrm{M}\right)$ was added to PHA lymphocytes in the presence of various concentrations of either anti-TAC or PE-anti-TAC. The binding of ${ }^{3} \mathrm{H}$-anti-TAC was reduced to a $50 \%$ level in the presence of $1.2 \times 10^{-9} \mathrm{M}$ antiTAC or $2.8 \times 10^{-8} \mathrm{M} \mathrm{PE-anti-TAC}$ (Table I). In a similar experiment, $7.4 \times 10^{-10} \mathrm{M}^{125} \mathrm{I}$-anti-TFR was added to HUT102 cells and displaced to a $50 \%$ level by $1.6 \times 10^{-7} \mathrm{M}$ antiTFR or $1.4 \times 10^{-7} \mathrm{M}$ PE-anti-TFR. Thus, the coupling of PE to anti-TAC reduced the binding activity of the antibody by 20 -fold, whereas the coupling of PE to anti-TFR had very little effect on its cellular binding.

\section{Discussion}

Anti-TAC, a monoclonal antibody that recognizes the $\mathrm{T}$ cell growth factor receptor, was chemically coupled to PE to make a cell-specific immunotoxin. At a concentration of $9 \times 10^{-10}$ M, PE-anti-TAC reduced protein synthesis by $50 \%$ after a 20 $h$ incubation with receptor-positive HUT-102 cells. Receptornegative MOLT -4 cells were unaffected by concentrations as high as $3 \times 10^{-8} \mathrm{M}$. While the MOLT-4 cells were refractory to PE-anti-TAC, they were sensitive to the action of another

Table I. Displacement of Labeled Antibody to 50\% Levels

\begin{tabular}{ll}
\hline $\begin{array}{l}\text { Labeled } \\
\text { antibody }\end{array}$ & $\begin{array}{l}\text { Concentration giving 50\% } \\
\text { reduction of binding }\end{array}$ \\
\hline${ }^{3} \mathrm{H}$-anti-TAC & $1.2 \times 10^{-9} \mathrm{M}$, anti-TAC \\
& $2.8 \times 10^{-8} \mathrm{M}$, PE-anti-TAC \\
& $1.6 \times 10^{-7} \mathrm{M}$, anti-TFR \\
& $1.4 \times 10^{-7} \mathrm{M}$, PE-anti-TFR
\end{tabular}

${ }^{3} \mathrm{H}$-anti-TAC was added to PHA-stimulated lymphocytes $\left(1 \times 10^{6}\right.$ cells) at a concentration of $3.5 \times 10^{-10} \mathrm{M}$. ${ }^{125} \mathrm{I}$-anti-TFR was added to HUT-102 cells $\left(1 \times 10^{6}\right)$ at a concentration of $7.4 \times 10^{-10} \mathrm{M}$. immunotoxin, PE-anti-TFR. Specificity of action was further confirmed by results that demonstrated the competitive reduction of PE-anti-TAC toxicity with the addition of excess antiTAC-antibody (Fig. 1). Thus, the difference in susceptibility to PE-anti-TAC between the two lines was due to the presence and absence of TCGF receptors and not to an entry defect in MOLT -4 cells that might not have allowed the expression of any immunotoxin.

The toxicity of PE-anti-TAC was enhanced 50- to 100fold in the presence of human adenovirus type II. When added to HUT-102 cells during a 4-h incubation $\left(37^{\circ} \mathrm{C}\right)$ period, the combination of $2 \mu \mathrm{g} / \mathrm{ml}$ of adenovirus and $1.5 \times 10^{-9} \mathrm{M}$ PEanti-TAC gave a $50 \%$ reduction in protein synthesis. In the same time period, PE-anti-TAC alone did not reduce protein synthesis by any $>20 \%$ even when present at $3 \times 10^{-8} \mathrm{M}$. We have shown previously that adenovirus enhances the toxicity of various toxin conjugates when these conjugates were constructed from ligands that entered cells via coated pits and receptosomes. We have shown also that toxins which are not capable of binding or being internalized into cells are not enhanced in activity to any great degree in the presence of adenovirus. Thus, it appeared adenovirus enhanced PE-antiTAC activity because this immunotoxin was cointernalized with the virus into coated pits and receptosomes.

To confirm this route of entry, we constructed a cytochemical conjugate by coupling HRP to the anti-TAC antibody. Anti-TAC-HRP was bound to HUT-102 cells in the cold, and entry followed after a warm-up step to $37^{\circ} \mathrm{C}$. Anti-TAC-HRP was observed to enter HUT-102 cells via coated pits at 1 min and was seen in receptosomes after $10 \mathrm{~min}$. A comparison was made with the entry of anti-TFR (anti-TFR-HRP), an antibody we had previously shown enters cells via coated pits and receptosomes (11). While both antibodies entered cells by the same route, anti-TFR-HRP was seen concentrated in both coated pits and receptosomes, while anti-TAC-HRP entered nonconcentratively. After $10 \mathrm{~min}$ of warming, there remained a strong uniform labeling of the HUT-102 cells' surface by anti-TAC-HRP.

Because we were interested in determining the pathway by which PE-anti-TAC entered cells, we had to prepare a suitable conjugate. HRP-anti-TAC was used because this conjugate is about the same size as PE-anti-TAC, and the HRP was coupled to anti-TAC in a similar manner to the way PE-antiTAC was prepared. Conjugates that used discrete markers such as colloidal gold were not used because colloidal gold conjugates are large and polyvalent and could affect the rate at which the antibody entered the cell or the pathway it followed once inside the cell $(20,21)$. Ferratin conjugates are also large and tend to have a higher degree of nonspecific binding than HRP conjugates.

Excess anti-TAC was used in competition studies to reduce the toxicity of PE-anti-TAC (Fig. 1). Anti-TAC at $1.8 \times 10^{-7}$ $M$ reduced the toxicity of PE-anti-TAC at $1.4 \times 10^{-8} \mathrm{M}$ by 50-fold. Since a 10-fold excess native antibody displaced toxicity 50-fold, we thought it necessary to examine the 
residual cell binding activity of each immunotoxin. Antibody binding activity of both the PE-anti-TAC and the PE-antiTFR was measured on PHA-stimulated lymphocytes and HUT-102 cells, respectively. PE-anti-TFR retained full binding activity while PE-anti-TAC lost the ability to displace ${ }^{3} \mathrm{H}-$ anti-TAC by a factor of 20 when compared with native anti-TAC.

While the cellular toxicity of PE- $\alpha$ TFR and PE-anti-TAC for HUT-102 cells were quite similar, there appear to exist several possibilities for further enhancing the activity of PEanti-TAC. More favorable reaction conditions might be established so that PE or another toxin could be coupled to antiTAC without loss of binding activity. Initially, anti-TAC does not appear to enter HUT-102 cells by a concentrative uptake mechanism. Presumably, a more rapid initial uptake of the PE-anti-TAC would lead to greater cell killing. This hypothesis could be tested if a specific agonist, such as interleukin 2 , induced receptor clustering and thereby increased the initial rate of internalization. Other anti-TAC antibodies may be isolated which induce clustering of the receptor in coated pits and thereby increase its uptake. Also it is possible that antiTAC may induce receptor clustering and concentrative uptake in other TCGF receptor positive cells.

\section{Acknowledgments}

We acknowledge the generous gifts of PE and the continuing support of this project by Steve Leppla. Our thanks to Joel Depper for his help with the ${ }^{3} \mathrm{H}$-anti-TAC binding study. We thank John Hanover for his critical reading of the manuscript. We are indebted to Maria Gallo and Angelina Rutherford for their excellent technical assistance, to R. M. Coggin for his typing and editorial assistance, and to Ray Steinberg for photographic reproductions.

\section{References}

1. Neville, D. M., and R. J. Youle. 1982. Monoclonal antibodyricin or ricin A chain hybrids: kinetic analysis of cell killing for tumor therapy. Immunol. Rev. 62:75-91.

2. Jansen, F. K., H. E. Blythman, D. Carriere, P. Casellas, O. Gros, P. Gros, J. C. Laurent, F. Paolucci, B. Pau, P. Poncelet, G. Richer, H. Vidal, and G. Voisin. 1982. Immunotoxins: hybrid molecules combining high specificity and potent cytotoxicity. Immunol. Rev. 62:185-216.

3. Vitetta, E. S., K. A. Krolick, M. Miyama-Inaba, W. Cushley, and J. W. Uhr. 1983. Immunotoxins: a new approach to cancer therapy. Science (Wash. DC). 219:644-650.

4. Trowbridge, I. S., and D. L. Domingo. 1981. Anti-transferrin receptor monoclonal antibody and toxin-antibody conjugates affect growth of human tumour cells. Nature (Lond.). 294:171-173.

5. Uchiyama, T., S. Broder, and T. A. Waldmann. 1981. A monoclonal antibody (anti-Tac) reactive with activated and functionally mature human T cells. I. Production of anti-Tac monoclonal antibody and distribution of Tac (+) cells. J. Immunol. 126:1393-1397.

6. Uchiyama, T., D. L. Nelson, T. A. Fleisher, and T. A. Waldmann. 1981. A monoclonal antibody (anti-Tac) reactive with activated and functionally mature human T cells. II. Expression of Tac antigen on activated cytotoxic $T$ cells, suppressor cells and one of two types of helper T cells. J. Immunol. 126:1398.

7. Leonard, W. J., J. M. Depper, T. Uchiyama, K. A. Smith, T. A. Waldmann, and W. C. Greene. 1982. A monoclonal antibody that appears to recognize the receptor for human T-cell growth factor; partial characterization of the receptor. Nature (Lond.). 300:267-269.

8. Leonard, W. J., J. M. Depper, R. J. Robb, T. A. Waldmann, and W. C. Greene. 1983. Characterization of the human receptor for T-cell growth factor. Proc. Natl. Acad. Sci. USA. 80:6957-6966.

9. Poeisz, B. J., F. W. Ruscetti, A. F. Gazdar, P. A. Bunn, J. D. Minna, and R. C. Gallo. 1980. Detection and isolation of type C retrovirus particles from fresh and cultured lymphocytes of a patient with cutaneous T-cell lymphoma. Proc. Natl. Acad. Sci. USA. 77:74157419.

10. Poeisz, B. J., F. W. Ruscetti, M. S. Reitz, V. S. Kalyanaraman, and R. C. Gallo. 1981. Isolation of a new type C retrovirus (HTLV) in primary uncultured cells of a patient with Sézary T-cell leukemia. Nature (Lond.). 294:268-271.

11. FitzGerald, D. J. P., I. S. Trowbridge, I. Pastan, and M. C. Willingham. 1983. Enhancement of toxicity of anti-transferrin receptor antibody-pseudomonas exotoxin conjugates by adenovirus. Proc. Natl. Acad. Sci. USA. 80:4134-4138.

12. FitzGerald, D. J. P., R. Padmanabhan, I. Pastan, and M. C. Willingham. 1983. Adenovirus-induced release of epidermal growth factor and pseudomonas toxin into the cytosol of KB cells during receptor-mediated endocytosis. Cell. 32:607-617.

13. Ey, P. L., S. J. Prowse, and C. R. Jenkin. 1978. Isolation of pure $\mathrm{IgG}_{1}, \mathrm{IgG}_{2 \mathrm{a}}$ and $\mathrm{IgG}_{2 \mathrm{~b}}$ immunoglobulins from mouse serum using protein A-sepharose. Immunochemistry. 15:429-436.

14. Haynes, B. F., M. Hemler, T. Cotner, D. L. Mann, G. S. Eisenbarth, J. L. Strominger, and A. S. Fauci. 1981. Characterization of a monoclonal antibody (5E9) that defines a human cell surface antigen of cell activation. J. Immunol. 127:347-351.

15. Green, M., and M. Pina. 1963. Biochemical studies on adenovirus multiplication. iv. Isolation, purification and chemical analysis of adenovirus. Virology. 20:199-207.

16. Tack, B. F., J. Dean, D. Eilat, P. E. Lorenz, and A. N. Schechter. 1980. Tritium labeling of proteins to high specific radioactivity by reductive methylation. J. Biol. Chem. 255:8842-8847.

17. Fraker, P. J., and J. C. Speck. 1978. Protein and cell membrane iodinations with a sparingly soluble chloroamide, 1,3,4,6-tetra-chloro3a,6a-diphenylglycoluril. Biochem. Biophys. Res. Commun. 80:849857.

18. Gootenberg, J. E., F. W. Ruscetti, J. W. Meir, A. Gazdar, and R. C. Gallo. 1981. Human cutaneous T-cell lymphoma and leukemia cell lines produce and respond to T cell growth factor. J. Exp. Med. 154:1403-1418.

19. Dales, S. 1973. Early events in cell-animal virus interactions. Bacteriol. Rev. 37:103-135.

20. Hopkins, C. R., and I. S. Trowbridge. 1983. Internalization and processing of transferrin and the transferrin receptor in human carcinoma cells A431. J. Cell Biol. 97:508-521.

21. Willingham, M. C., J. A. Hanover, R. B. Dickson, and I. Pastan. 1984. Morphologic characterization of the pathway of transferrin in endocytosis and recycling in human KB cells. Proc. Natl. Acad. Sci. USA. 81:175-179.

22. Depper, J., W. Leonard, M. Kronke, T. A. Waldmann, and W. C. Greene. 1984. Augmented T-Cell Growth Factor Receptor Expression in HTLV Infected Human Leukemic T-Cells. J. Immunol. In press. 